\title{
Textural, Structural and Electrical Characterizations of EMIMAc Silica Ionogels and Their Corresponding Aerogels
}

\author{
Nadjette Bengourna ${ }^{3}$, Florence Despetis ${ }^{1,2}$, Laurent Bonnet ${ }^{1,2}$, Rémi Courson $^{4,5}$, Pierre Solignac ${ }^{1,2}$, Hamid Satha ${ }^{3}$ \\ \& Nathalie Olivi-Tran ${ }^{1,2}$ \\ ${ }^{1}$ Laboratoire Charles Coulomb, CNRS, UMR 5221, place Eugene Bataillon, 34095 Montpellier cedex 5, France \\ ${ }^{2}$ Laboratoire Charles Coulomb, Universite Montpellier 2, place Eugene Bataillon, 34095 Montpellier cedex 5, \\ France \\ ${ }^{3}$ Laboratoire des Silicates, Polymeres et des Nanocomposites, Universite 8 mai 1945, BP 401, Guelma, Algerie \\ ${ }^{4}$ CNRS, LAAS, 7 avenue du colonel Roche, Toulouse, France \\ ${ }^{5}$ Universit de Toulouse, LAAS, Toulouse, France \\ Correspondence: Nathalie Olivi-Tran, Laboratoire Charles Coulomb, CNRS, UMR 5221, place Eugene Bataillon, \\ 34095 Montpellier cedex 5, France. E-mail: Nathalie.Olivi-Tran@univ-montp2.fr
}

Received: November 13, 2013 Accepted: January 14, 2014 Online Published: June 13, 2014

doi:10.5539/apr.v6n4p16 URL: http://dx.doi.org/10.5539/apr.v6n4p16

\begin{abstract}
Silica ionogels were synthesized from tetramethoxysilane (TMOS), methyltrimethoxysilane (MT MS) and 1-ethyl2-methylimidazolium Acetate (EMIMAc: Ionic Liquid) in different proportions .The textural characterizations showed an effect of these concentrations on the corresponding aerogels: pore size distributions and effective surfaces. The structure of the aerogels was measured with a SAXS (Small- Angle XRay Scattering) apparatus and was typical of acid catalyzed aerogels. Conductivity voltage measurements, operated on the ionogels, were carried out using an electrical 4 wire-electrodes set up. The electrical voltage temporal response of the EMIMAc silica ionogel was modelled by a RLC series circuit which characteristics depended on the synthesis.
\end{abstract}

Keywords: ionogels, structure and texture, conductivity

\section{Introduction}

Ionic liquids (IL) are molten salts which are liquid at a temperature lower than $100{ }^{\circ} \mathrm{C}$. Since the first $\mathrm{IL}$ synthesis, chemists and material scientists have been highly interested in this new type of conducting liquids because of their numerous properties and potential applications like green solvent, electrolytes, sensors, catalysts or batteries (Galinski et al., 2006; Rakita, 2003; Keskin et al., 2007). It is also possible to synthesize nano-composites materials by mixing IL with silica precursors, via a sol gel route. The first ionogel (for gel synthesized with an IL) was obtained in 2000 by Dai et al. (2000). Several investigations led to a variety of materials (Vioux et al., 2010; Neouze et al., 2005; Karout et al., 2007; Klingshirn et al., 2005) implying numerous characterizations: porous volume, fractal dimension, conductivity of the ionogel bulk measured with two plate electrodes (Gupta et al., 2012; Neouze et al., 2006; Karout et al., 2009a, 2009b; Zhang et al., 2010; Zhou et al., 2004).

Asymmetric cation, N,Ndialkylimidazolium or 1-butyl-3-methylimidazolium associated with anions such as tetrafluoroborate, were the most commonly IL used for a few years (Gupta et al., 2012; Shi et al., 2005). Here we chose to work with another imidazolium cation, 1-ethyl-2-methylimidazolium bonded to the anion acetate (EMIMAc). This IL exhibits a high electric conductivity $(2500 \mu \mathrm{S} / \mathrm{cm})$ at ambient temperature (www.ilco-chemie.de, Francois, 2006).

The present study is focused on the synthesis and the characterization of EMIMAc silica ionogels and their corresponding aerogels.

Textural and structural characterizations as nitrogen adsorption/desorption and SAXS were carried out on the aerogels. Hence, porous volume and texture were obtained together with the structure of the silica solid network.

Then, by a 4-wire-electrodes set up, we measured the temporal response of our ionogels to a voltage pulse and we 
modeled these responses by a RLC circuit. Up to now, only three studies on ionogels conductivity were performed (Neouze et al., 2005, 2006; Goeury et al., 2001) and none of them gave the electrical temporal response of ionogels.

\section{Experimental Set-Up}

\subsection{Synthesis of the Ionogels and Aerogels}

\subsubsection{Chemicals}

The ionic liquid: 1-Ethyl-3methylimidazolium acetate $(E M I M A c)$ of purity $>90 \%$, and the silica precursors, tetramethoxysilane TMOS (98\%) and methyltrimethoxysilane MTMS (98\%), were from Aldrich. Technical grade ethanol was used to extract water and IL from the gel before the $\mathrm{CO}_{2}$ supercritical drying. Because of the hydrophilicity of our IL, this last was heated under vacuum $\left(70{ }^{\circ} \mathrm{C}, 10 \mathrm{mbar}\right)$ for $48 \mathrm{~h}$ before each synthesis. Gels were prepared via an hydrolytic one step process by mixing two solutions: solution (1) with TMOS and MTMS in different molar ratios and solution (2) containing IL and acidic water ( $\mathrm{HCl}$ concentration equal to $0.65 \mathrm{~N}$ ). The molar ratio $n I L / n S i$ was set between 0.3 and 0.6 and for each sample, the hydrolysis molar ratio $n$ water $/ n S i$ was equal to 16 . After stirring, the mixture was poured into the conductivity cell and in molds for further characterizations of the ionogels. Gelling occurred after a time which depended on the IL ratio and the MT MS ratio (Brinker \& Scherer, 1990). Gels were transparent disks with a diameter of $16 \mathrm{~mm}$ and a height of 4 $m m$ without any cracks. All these steps were done at $22 \pm 2{ }^{\circ} \mathrm{C}$. Table 1 lists the different samples synthesized by varying proportions of IL and of MTMS.

\subsection{2 $\mathrm{CO}_{2}$ Supercritical Drying}

The knowledge of the texture and the structure of ionogels imply their drying under conditions which allow to obtain dry materials exhibiting properties very close to these of the ionogels. For these reasons, drying must be carried out under supercritical conditions to avoid capillary stresses which would lead to dense and cracked materials. For the same reasons and to avoid the dissolution/redeposition phenomenon which occurs at high temperature and which can induce textural modifications at a very low scale (Quinson et al., 1992), we chose to dry the gels using supercritical $\mathrm{CO}_{2}$ so-called $\mathrm{COLD}$ process. The wet gels were aged during $12 \mathrm{~h}$. For $\mathrm{CO}_{2}$ supercritical drying, the liquid that impregnates the wet gels must exhibit a total miscibility with $\mathrm{CO}_{2}$. So, the wet gels, which contained water and the IL, were first soaked into ethanol for 15 days to obtain gels with pores mainly filled by ethanol. Then the ethanol was exchanged with liquid $\mathrm{CO}_{2}$ at $8{ }^{\circ} \mathrm{C}$ and $6 \mathrm{MPa}$ during 5 hours. Finally, temperature and pressure were raised to $38^{\circ} \mathrm{C}$ and $10 \mathrm{MPa}$ and after $10 \mathrm{~min}$, the pressure was released slowly during $12 \mathrm{~h}$. Samples obtained were translucent (Figure 1) without any cracks and exhibited a shrinkage which depended on the composition of the gel.

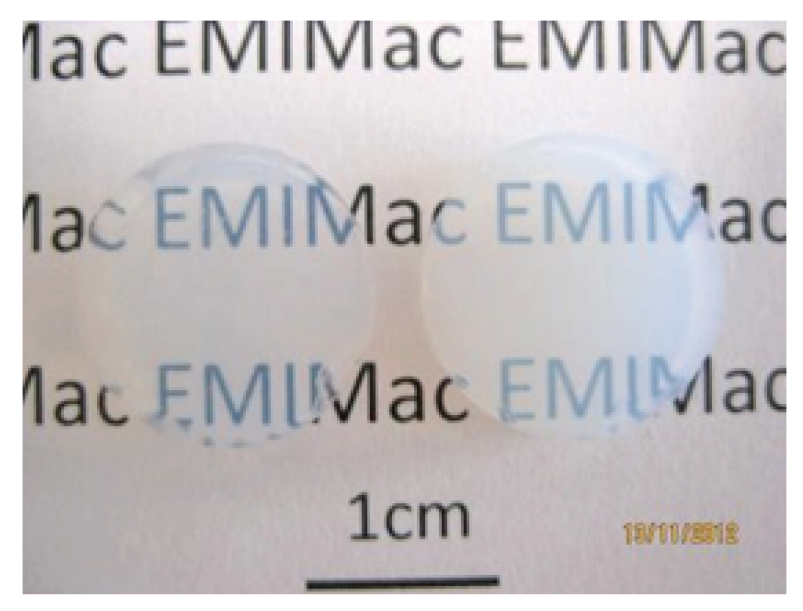

Figure 1. Photographs of synthesized aerogels, left: sample (A); right: sample (C)

\subsection{Characterization methods}

\subsubsection{Textural and Structural Characterizations of the Aerogels}

The bulk densities of the samples were evaluated from their weight and linear dimensions. For the textural characterization, nitrogen adsorption/desorption isotherms at $77 \mathrm{~K}$ were carried out on a Micromeritic ASAP2010. 
Samples were out-gassed under vacuum during $16 \mathrm{~h}$ at $50{ }^{\circ} \mathrm{C}$. The specific surface area was obtained using BET theory. Its accuracy was about $4 \%$. For rigid porous materials, when the nitrogen relative pressure $P / P_{0}$ gets close to 0.99 , the volume of adsorbed nitrogen must correspond to the porous volume (Reichenauer et al., 2001). The dwell time, which is the interval of time allowing a pressure change of $0.01 \%$, was set to 10 seconds. The pore size distributions were derived from BJH method from the desorption branches of the isotherm. SAXS (small angle X ray scattering) and WAXS (wide angle $X$ ray scattering) experiments were performed with an in-house setup of the Laboratoire Charles Coulomb, using an X-ray tube GeniX3D from Xenocs and a Schneider 2D image-plate detector prototype, in order to estimate the fractal dimension of the materials.

Table 1. Compositions and gelation times for the studied samples

\begin{tabular}{ccccc}
\hline Sample & $n_{I L} / n_{S i}$ & $\begin{array}{c}\text { molar ratio } \\
n_{M T M S} / n_{T M O S}\end{array}$ & Sol pH & Gelation time \\
\hline $\mathrm{A}$ & 0.3 & 0 & 4.5 & $25 \mathrm{~min}$ \\
$\mathrm{~B}$ & 0.3 & 0.2 & 4.5 & $35 \mathrm{~min}$ \\
$\mathrm{C}$ & 0.3 & 0.4 & 4.5 & $2 \mathrm{~h} 40$ \\
$\mathrm{D}$ & 0.45 & 0.4 & 5 & $1 \mathrm{~h} 40$ \\
$\mathrm{E}$ & 0.6 & 0.4 & 5.5 & $1 \mathrm{~h}$ \\
\hline
\end{tabular}

\subsubsection{Electrical conductivity measurements}

These measurements were performed on ionogels using a set up described on Figure 2.

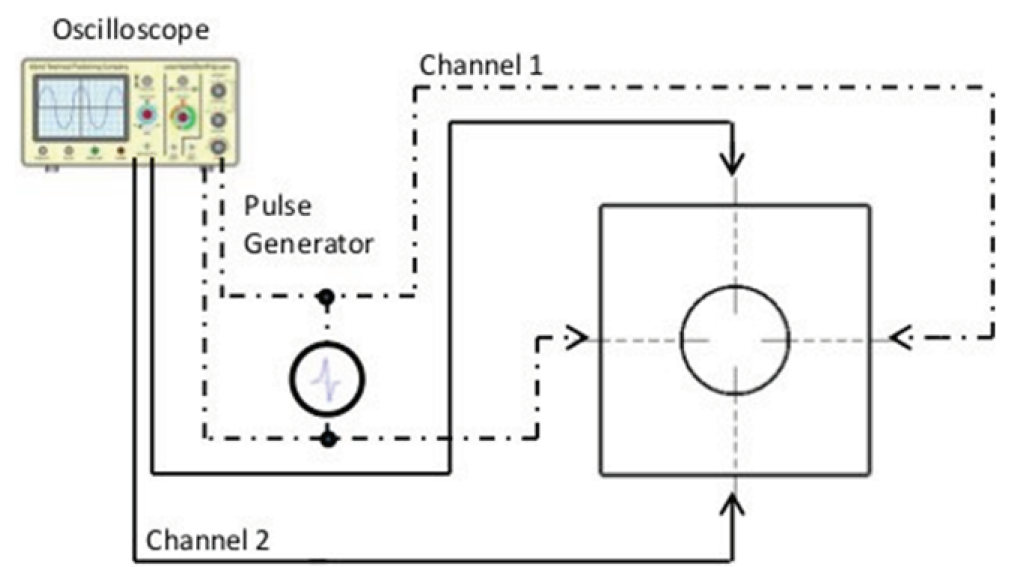

Figure 2. Experimental set-up for the electrical voltage characterization of the ionogel. The ionogel sample is represented by the disk with 4 electrodes getting through the square mold

The cylindrical cell allowing these measurements consisted of a Teflon mold containing the ionogel and of 4 Ptelectrodes partially immersed in the ionogel and passing through the sides of the mold. The 4 electrodes were $P t$ wires with a section of $0.5 \mathrm{~mm}$. These wires were immersed in the bulk of gels along $7 \mathrm{~mm}$ and fixed to the mold to make sure that all the measurements were done in the same conditions. The mold was cylindrical with a depth of $5 \mathrm{~mm}$ and a diameter of $15 \mathrm{~mm}$. The 4 wires were connected to a pulse generator (Aligent 33220A, $20 \mathrm{MHz}$, Arbitrary waveform generator) and to an oscilloscope (TDS2022C, $200 \mathrm{MHz}$, Tektronik).

A rectangular voltage pulse was applied between 2 (channel 1) of the 4 electrodes. Then the potential difference was measured between these 2 electrodes (channel 1) and between the 2 other ones (channel 2). First, we measured the electrochemical domain of stability of the EMIMAc. We found that for an applied potential equal to $4 \mathrm{~V}$ and an offset equal to $-1.375 \mathrm{~V}$, there was oxido-reduction of the IL at room temperature. We checked that for an applied potential equal to $2.5 \mathrm{~V}$ and an offset equal to $-1.25 \mathrm{~V}$, the IL was stable. Straightforwardly, we chose to study the electrical temporal response of our ionogel samples at this voltage. The voltage pulses had an absolute value of $3.75 \mathrm{~V}$ (applied potential $2.5 \mathrm{~V}$ plus offset $1.25 \mathrm{~V}$ ), a frequency of $50 \mathrm{~Hz}$ and pulse durations of either $20 \mathrm{~ns}$ or $100 \mathrm{~ns}$. 
This allowed us to measure the electrical response of the solvent (IL, HCl, water) contained in the porous network of the ionogels. Indeed, as the diameter of the electrodes was smaller than the depth of the set up (i.e., smaller than the height of the ionogel cylinder), these electrodes were always in contact with the IL contained in the pores. As we applied rectangular voltage pulses to the ionogel, we were able to analyze the temporal response of the sample.

In order to analyze the role of the silica network, a blank was first done on EMIMAc $+H C l$ solution. Then electrical voltage measurements were performed on the ionogel samples within 1 hour after gelling occurred.

\section{Results}

\subsection{Textural and Structural Characterizations}

The relative shrinkage which occurred during the different steps, from the gel to the aerogel, and the characteristics of the aerogels are presented in Table 2. Most of the samples exhibited low densities and high specific surface areas. The specific surface area showed a tendency to increase up to a maximum value with a higher ratio of $n M T M S / n T M O S$ but it did not change with the IL concentration. A divergence between the measured porous volume $V_{m p}$ and the calculated one $V_{c p}$ was observed. As reported in the literature (Reichenauer et al., 2001), when the density of the aerogel is low, it is more difficult to explore the whole porous volume by adsorption/desorption. We must also note that some IL remained inside the aerogels ( $\propto 5 \%$ in weight) as already described in the literature (Karout et al., 2009).

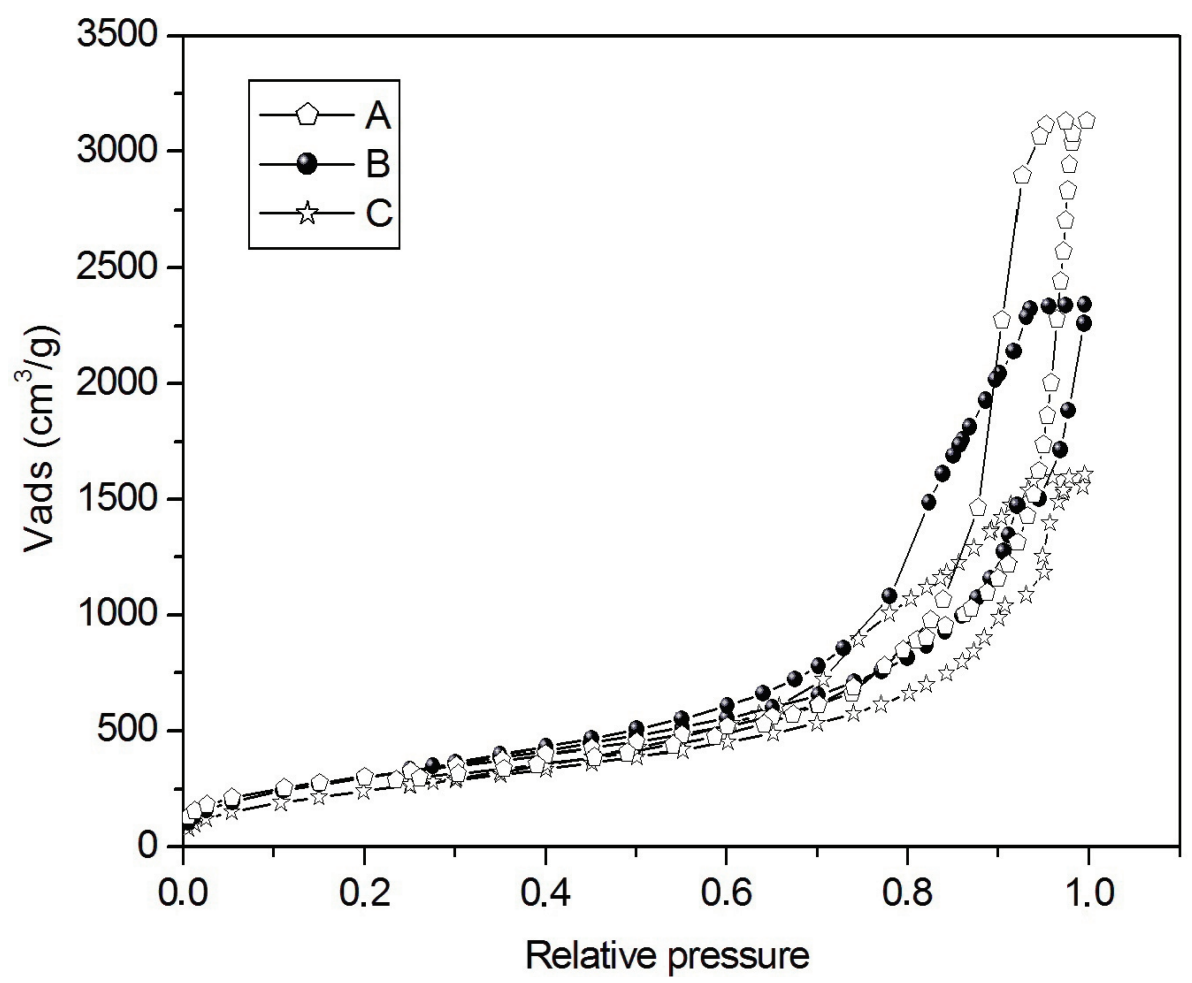

Figure 3. Adsorption/Desorption isotherms 
Table 2. Shrinkage observed after each step of the drying and characteristics of the aerogels. ${ }^{*} V_{c p}$ is calculated from the bulk density and the skeletal density of silica which has been estimated in the literature to about $2 \mathrm{~g} \cdot \mathrm{cm}^{-3}$ in silica aerogels (Ayral et al., 1992)

\begin{tabular}{llllllll}
\hline Sample & $\begin{array}{l}\text { Shrinkage } \\
\text { after soaking } \\
\pm 0.1(\%)\end{array}$ & $\begin{array}{l}\text { Shrinkage } \\
\text { after drying } \\
\pm 0.1(\%)\end{array}$ & $\begin{array}{l}\text { Bulk den- } \\
\text { sity } \pm 0.002 \\
\left(g \cdot \mathrm{cm}^{-3}\right)\end{array}$ & $\begin{array}{l}\text { Calculated } \\
\text { pore vol- } \\
\text { ume } V_{c p} \pm \\
0.1\left(\mathrm{~cm}^{3} \cdot g\right)\end{array}$ & $\begin{array}{l}\text { Desorption } \\
\text { BJH polume } V_{m p} \pm \\
\text { vore }\end{array}$ & $\begin{array}{l}V_{m p} / V_{c p} \\
(\%)\end{array}$ & $\begin{array}{l}\text { Specific } \\
\text { surface } \\
\text { area } \\
\left(\mathrm{cm}^{3} \cdot g\right)\end{array}$ \\
\hline A & 13.6 & 14.3 & 0.288 & 3.0 & 2.82 & 95 & $640 \pm 25$ \\
B & 3 & 8.1 & 0.192 & 4.7 & 3.14 & 67 & $885 \pm 35$ \\
C & 6 & 9.3 & 0.198 & 4.5 & 2.94 & 65 & $1090 \pm 40$ \\
D & 6.6 & 7.8 & 0.173 & 5.3 & 3.29 & 62 & $1040 \pm 40$ \\
E & 6.4 & 7 & 0.167 & 5.5 & 3.22 & 59 & $1050 \pm 40$ \\
\hline
\end{tabular}
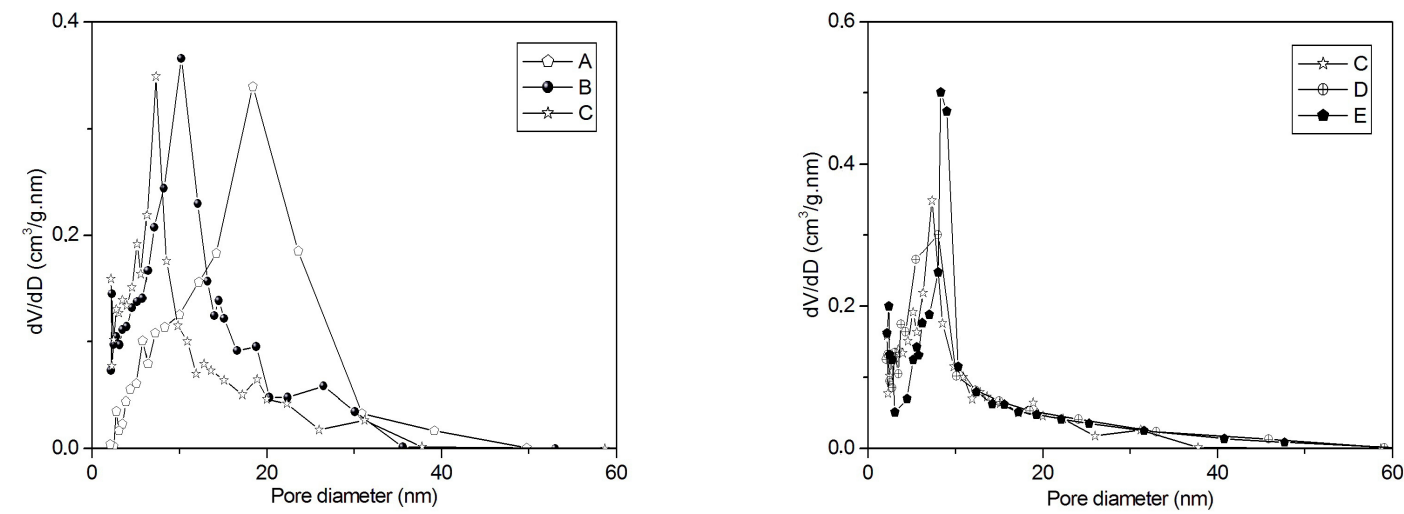

Figure 4. Pore size distributions obtained from BJH method. left: Effect of the MTMS/TMOS ratio; right: Effect of the IL ratio

Nitrogen adsorption isotherms are given in Figure 3 for three compositions. The pore size distributions, reported in Figures 4, are calculated from the isotherms. Aerogel made without $M T M S$ displayed a larger pore size distribution. This distribution is increasingly narrow and shifted to lower diameters when the $M T M S$ ratio is increasing (Figure 4 left). However, distributions do not vary when the IL ratio increases (Figure 4 right).
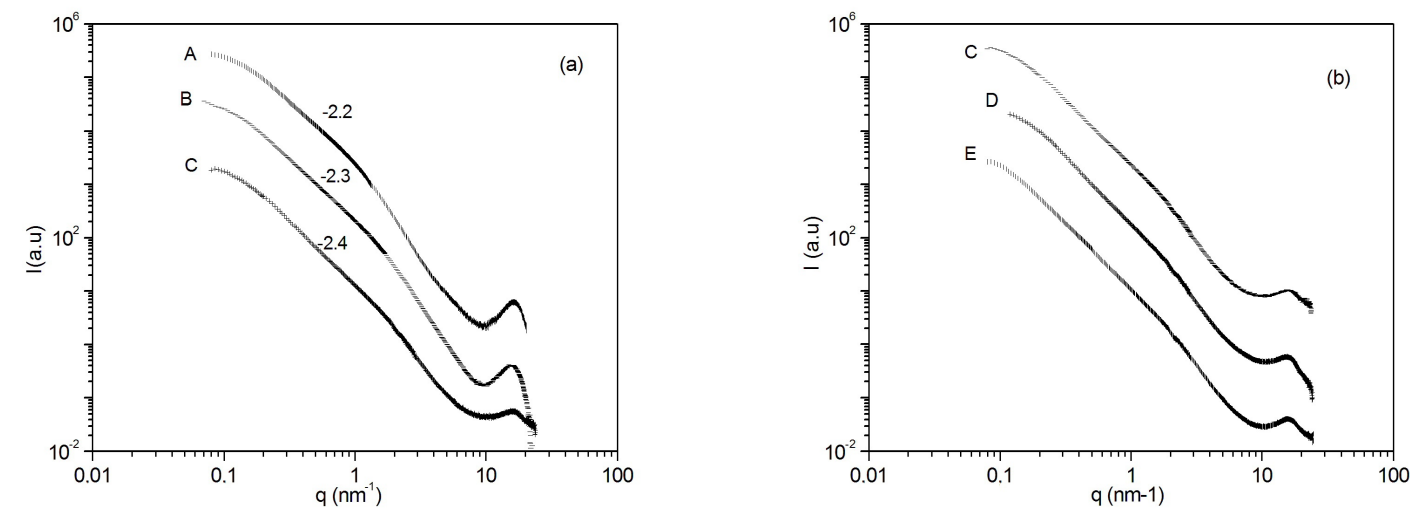

Figure 5. SAXS/WAXS curves. left: Effect of the MTMS ratio; right: Effect of IL ratio 
All the ionogels synthesized are fractal ones even if the fractal domain is relatively small (one decade)(Figures 5).The fractal dimension is enclosed between 2.2 and 2.5, values which are characteristic of acid catalyzed aerogels. Samples C, D and E exhibit the same behavior with a larger fractal domain than sample A or B, and a fractal value around 2.5 .

\subsection{Conductivity: Electrical Voltage Characterization}

The maximum of the measured amplitudes on both channels 1 and 2 are presented in Table 3 for all the samples. Examples of electrical voltage temporal responses of the ionogels lead to Figures 6 and 7.

- For an input pulse duration of $20 \mathrm{~ns}$, the maximum of the response on channel 1 for all the ionogel samples was close to the value of the input voltage, within experimental fluctuations

- For an input pulse duration of $100 \mathrm{~ns}$, the maximum of the response on channel 1 for all the ionogel samples was larger than the input voltage

- For both durations, on channel 2, all the responses were damped.

- For the system EMIMAc $+\mathrm{HCl}$ solution, the maximum of the response on channel 1 was lower than the input pulse but with oscillations whatever the pulse duration.

- Samples A, B, C, D, E have the same response on channel 1 within experimental variations

- Samples B, C, D, E have the same response on channel 2 within experimental variations

- Sample A has a response on channel 2 which is damped with respect to samples B, C, D, E and EMIMAc + $\mathrm{HCl}$ solution.

An electrical modeling of these responses is presented in section Discussion.

\section{Discussion}

The presence of MTMS (hydrophobic groups) in the sol postpones the hydrolysis and condensation reactions and thus increases the gelation time (Schwertfeger et al., 1992). For samples C to E, the IL ratio increases and the associated $p H$ increase enhances polycondensation reactions (Pope \& Mackenzie, 1986) and thus the gelling time decreases (Schwertfeger et al., 1992).
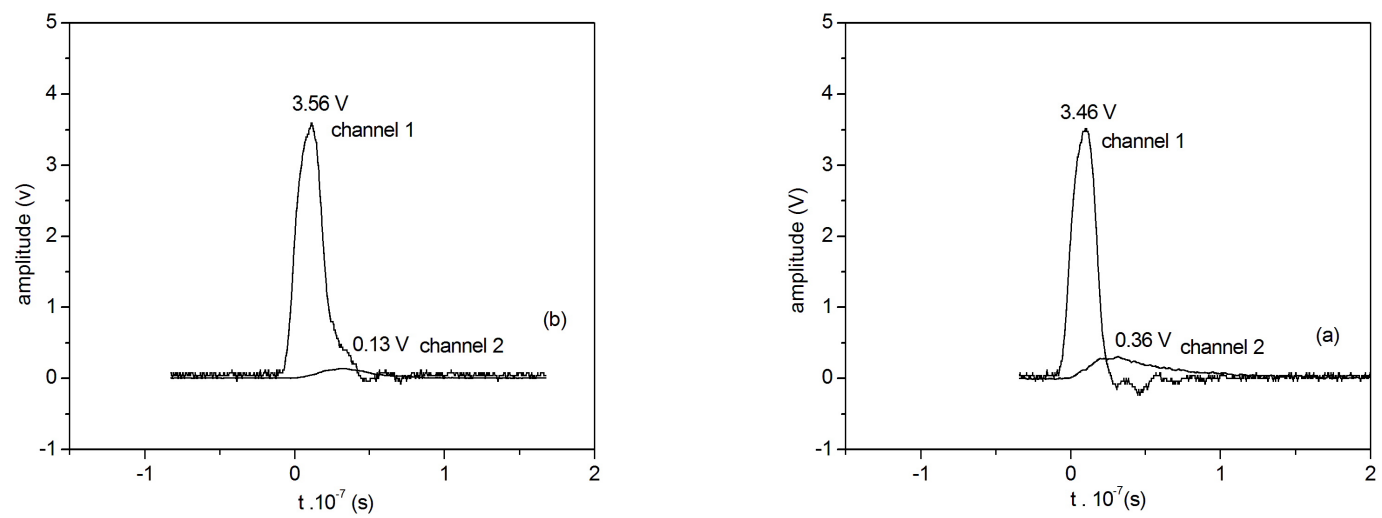

Figure 6. Electrical voltage temporal responses to a rectangular voltage pulse (for a total amplitude of $\mathrm{V}=3.75 \mathrm{~V}$ and a duration of $\mathrm{t}=20 \mathrm{~ns}$ ). left: for sample A; right: for an EMIMAc $+\mathrm{HCl}$ solution 

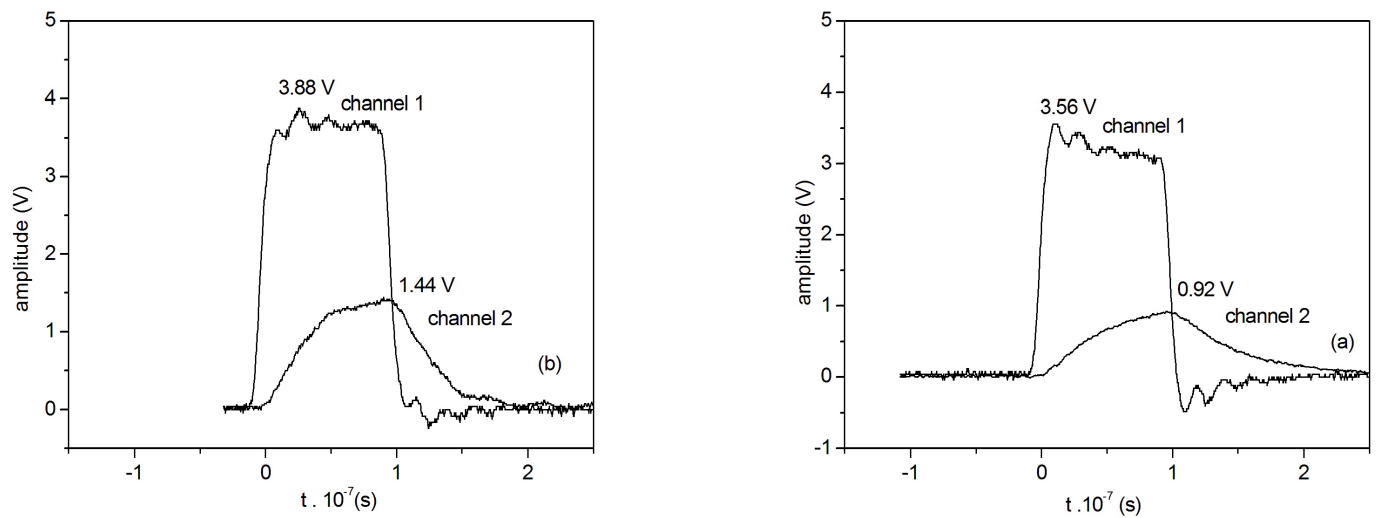

Figure 7. Electrical voltage temporal response to a rectangular voltage pulse (of total amplitude $3.75 \mathrm{~V}$ and duration $100 \mathrm{~ns}$ ); left: for sample E; right: for an EMIMAc $+\mathrm{HCl}$ solution

Table 3. Voltage maxima at different conditions (in $V$ )

\begin{tabular}{ccccc}
\hline \multirow{2}{*}{ Sample } & \multicolumn{2}{c}{ 20 ns } & \multicolumn{2}{c}{$100 \mathrm{~ns}$} \\
\cline { 2 - 5 } & Channel 1 & Channel 2 & Channel 1 & Channel 2 \\
\hline A & 3.56 & 0.13 & 4.08 & 0.29 \\
B & 3.58 & 0.68 & 4.08 & 1.54 \\
C & 3.56 & 0.67 & 4 & 1.52 \\
D & 3.52 & 0.58 & 3.88 & 1.44 \\
E & 3.52 & 0.536 & 3.84 & 1.38 \\
EMIMAc+HCl & 3.46 & 0.36 & 3.56 & 0.92 \\
\hline
\end{tabular}

It is worth noting that the shrinkage after drying is rather low $(<10 \%)$ for all the investigated samples except sample A. For sample A, which is synthesized without $M T M S$, the soaking governs the shrinkage amplitude (Brinker \& Scherer, 1990). Capillary tensions induced by IL exchange are probably overcoming the strength of the silica network. For the other samples, the $M T M S$ induces a repulsive wall/liquid effect (stable $\mathrm{Si}-\mathrm{CH}_{3}$ groups on the surface of $\mathrm{SiO}_{2}$ particles) and thus reduces the capillary tensions (Schwertfeger et al., 1992). Consequently shrinkage decreases slightly as the increase of the MTMS content.

For samples A, B and C, the methyl modification obviously acts on the specific surface area which increases with the MTMS ratio. For the sample without $M T M S$, the fractal dimension is slightly smaller and the fractal domain is narrower. MT MS reduces cross-linkage and make the clusters grow slowly (Venkateswara et al., 2001). Regarding the aerogel texture, it is clear that while $n M T M S / n T M O S$ value increases, the pore size distribution decreases towards the smaller pore sizes and becomes narrower (Neouze, 2005). Hence, EMIMAc and MT MS induce noteworthy changings in the textures or structures of the aerogels, the effects on conductivities are shown below. Though the bulk density of samples C, D and E varies from 0.16 to $0.2 \mathrm{~g} \cdot \mathrm{cm}^{-3}$ depending on the IL ratio, their specific surface area and pore size distribution do not depend on the density. Their structures are very similar (Figure 5 right and Table 2).

The electrical voltage response of our ionogel samples is typical of a RLC series circuit. We show here in Figures 8 a few examples of RLC series circuits signals to which a rectangular voltage pulse is applied.

The shape of the response which is taken at the capacity component $(\mathrm{C})$ in the simulation depends on the duration of the voltage pulse: if the duration of the input pulse is too short, the sample is in the electrical voltage transient state, this is the case for pulse durations equal to $20 \mathrm{~ns}$ in the experiments and $0.1 \mathrm{~s}$ in the simulations. For longer pulse durations (here 100ns in the experiments and $0.4 \mathrm{~s}$ in the simulations), we are in the permanent regime. In the case of responses measured on channel 2 (see section Results), the damping is due to the direction of the applied potential (perpendicular to channel 2). 

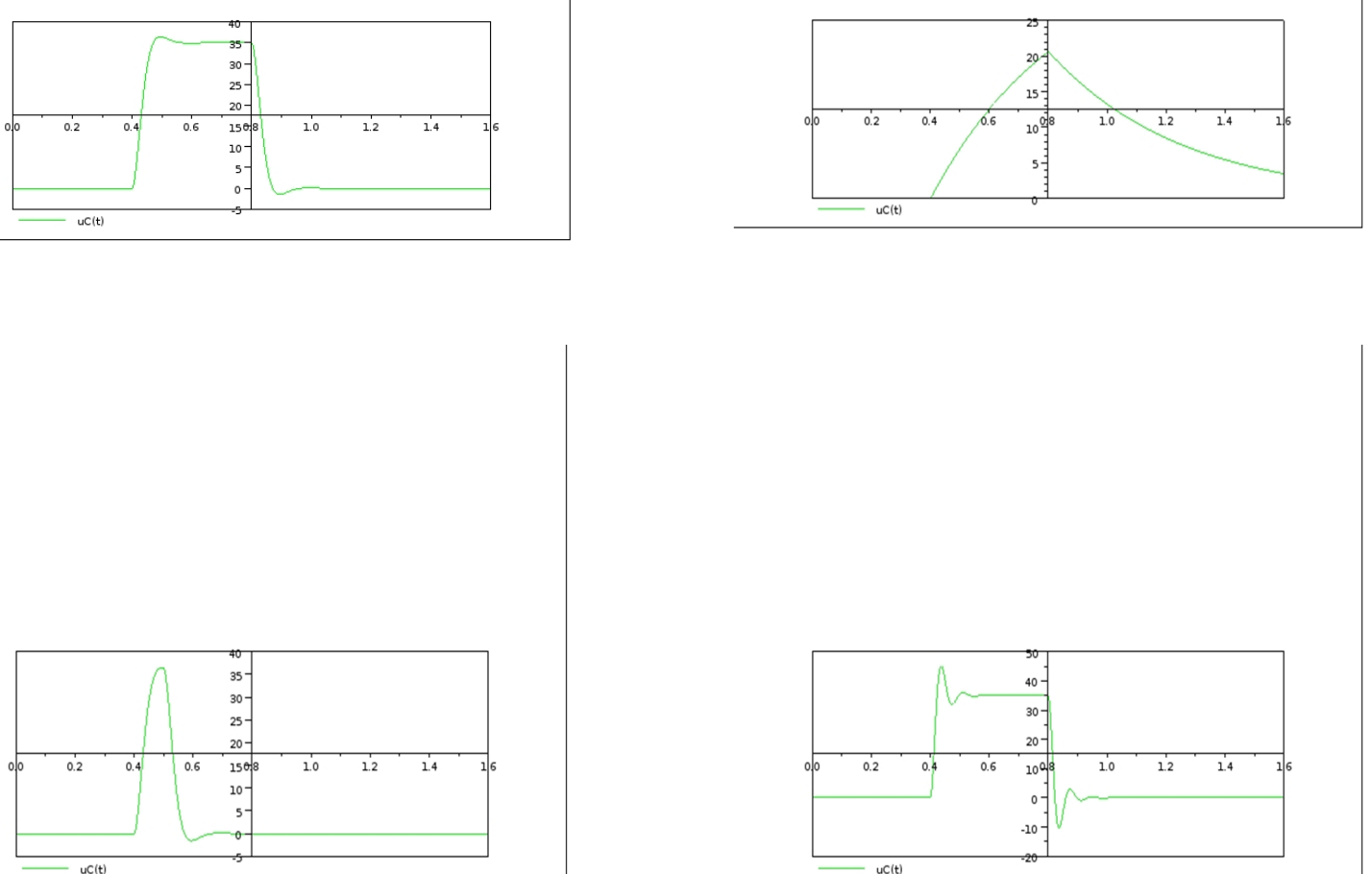

Figure 8. Results of the calculations of the response to a voltage pulse of a RLC circuit: values of the components. top left: $\mathrm{R}=100 \Omega, \mathrm{L}=1.5 \mathrm{H}, \mathrm{C}=0.0003 \mathrm{~F}, \Delta=0.4 \mathrm{~s}$; bottom left: $\mathrm{R}=100 \Omega, \mathrm{L}=1.5 \mathrm{H}, \mathrm{C}=0.0003 \mathrm{~F}, \Delta \mathrm{t}=0.1 \mathrm{~s}$; top right: $\mathrm{R}=1500 \Omega, \mathrm{L}=1.5 \mathrm{H}, \mathrm{C}=0.0003 \mathrm{~F}, \Delta \mathrm{t}=0.4 \mathrm{~s}$; bottom right: $\mathrm{R}=100 \Omega, \mathrm{L}=1.5 \mathrm{H}, \mathrm{C}=8.10-5 \mathrm{~F}, \Delta \mathrm{t}=0.4 \mathrm{~s}$

What is worth noting, is the difference between the responses of the ionogels samples and that of the $\mathrm{HCl}+\mathrm{IL}$ solution: the highest amplitudes of the ionogels electrical voltage responses on channel 1 are always larger than the responses of the $\mathrm{HCl}+\mathrm{IL}$ solution. For the ionogels synthesized with $M T M S$, channel 2 shows maxima which are larger than the HCL+IL solution; but for sample A (without $M T M S$ ), channel 2 is lower than the blank.

Finally, we characterized the texture and the structure of EMIMAc silica ionogels as well as their temporal conductivity. We showed that depending on the amount of MTMS and EMIMAc, the structures, textures and electrical voltage responses were different.

\section{Conclusion}

We synthesized ionogels from TMOS, MTMS and EMIMAc. Aerogels were obtained from supercritical drying of our ionogels. The texture and the structure were performed on these aerogels by Nitrogen adsorption/desorption and SAXS. An electrical characterization was performed on the ionogels with a 4-wire-electrodes set-up. This characterization allowed us to model the ionogels by a RLC series circuit. The texture and structure of the aerogels and the electrical voltage characteristics of the ionogels all depended on the different amounts of TMOS, MTMS and EMIMAc used in the synthesis.

\section{References}

Ayral, A., Phalippou, J., \& Woignier, T. (1992). Skeletal density of silica aerogels determined by helium pycnometry. J. Mater. Science, 27(5), 1166-1170. http://dx.doi.org/10.1007/BF01142014 
Brinker, J. F., \& Scherer, G. W. (1990). Sol-gel Science. New-York: Academic Press.

Dai, S., Ju, Y. H., Gao, H. J., Lin, J. S., Pennycook, S. J., \& Barnes, C. E. (2000). Preparation of silica aerogel using ionic liquids as solvents. Chem. Comm., 3, 243-244. http://dx.doi.org/10.1039/A907147D

Francois, Y. (2006). PhD thesis University Paris VI (p. 32).

Galinski, M., Lewandowski, A., \& Stepniak, I. (2006). Ionic liquids as electrolytes. Electrochimica Acta, 51(26), 5567-5580. http://dx.doi.org/10.1016/j.electacta.2006.03.016

Goeury, C., Hedjiedj, A., \& Nadi, M.,(2001). A conducting gel for electrical simulation of human tissues between 50 H 500 kHz. ITBM-RBM, 22(6), 371-377. http://dx.doi.org/10.1016/S1297-9562(01)90012-9

Gupta, A. K., Singh, M. P, Singh, R. K., \& Chandra, S. (2012). Low density ionogels obtained by rapid gellification of tetraethyl orthosilane assisted by ionic liquids. Dalton Trans., 41, 6263-6271. http://dx.doi.org/10.1039/C2DT30318C

ILCO Chemikalien. (2008). Table of Ionic Liquids properties. Retrieved from http://www.ilco-chemie.de/downloads/ Ionic Liquids.pdf

Karout, A., \& Pierre, A. C. (2007). Silica xerogels and aerogels synthesized with ionic liquids. J. Non-Cryst. Solids, 353(30-31), 2900C2909. http://dx.doi.org/10.1016/j.jnoncrysol.2007.06.024

Karout, A., \& Pierre, A. C. (2009a). Silica gelation catalysis by ionic liquids. Catalysis Communications, 10(4), 359-361. http://dx.doi.org/10.1016/j.catcom.2008.07.046

Karout, A., \& Pierre, A. C. (2009b). Porous texture of silica aerogels made with ionic liquids as gelation catalysts. J. Sol-Gel Sci. Technol., 49(3), 364-372. http://dx.doi.org/10.1007/s10971-008-1873-2

Keskin, S., Kayrak-Talay, D., Akman, U., \& Hortacsu, O. (2007). A review of ionic liquids towards supercritical fluid applications. J. of Supercritical Fluids, 43(1), 150-180. http://dx.doi.org/10.1016/j.supflu.2007.05.013

Klingshirn, M. A., Spear, S. K., Holbrey, J. D., \& Rogers, R. D. (2005). Ionic liquids as solvent and solvent additives for the synthesis of sol-gel materials. J. Mater. Chem., 15, 5174-5180. http://dx.doi.org/10.1039/B508927A

Neouze, M. A., Le Bideau, J., \& Vioux, A. (2005). Versatile heat resistant solid electrolytes with performances of liquid electrolytes. Progress in Solid State Chemistry, 33(2-4), 217-222. http://dx.doi.org/10.1016/ j.progsolidstchem.2005.11.049

Neouze, M. A., Le Bideau, J., Leroux, F., \& Vioux, A. (2005). A route to heat resistant solid membranes with performances of liquid electrolytes . Chem. Commun., 2005, 1082-1084. http://dx.doi.org/10.1039/B416267F

Neouze, M. A. (2005). The birth of topological insulators. Ionogels obtenus par confinement dun liquide ionique dans une matrice base de silice, PhD thesis, University Montpellier 2.

Neouze, M. A., Le Bideau, J., Gaveau, P., Bellayer, S., \& Vioux, A. (2006). Ionogels, New Materials Arising from the Confinement of Ionic Liquids within Silica-Derived Networks. Chem. Mater., 18(17), 3931-3936. http://dx.doi.org/10.1021/cm060656c

Pope, E. J. A., \& Mackenzie, J. D. (1986). Sol-gel processing of silica: II. The role of the catalyst. J. Non-Cryst. Solids, 87(1-2), 185-198. http://dx.doi.org/10.1016/S0022-3093(86)80078-3

Quinson, J. F., Pauthe, M., Lacroix, M., Woignier, T., Phalippou, J., \& Hdach, H. (1992). Silica alcogels prepared under neutral conditions: hypercritical treatment effect on textural and mechanical properties. J. NonCryst.Solids, 147-148, 699-703. http://dx.doi.org/10.1016/S0022-3093(05)80702-1

Rakita, P. E. (2003). Challenges to the Commercial Production of Ionic Liquids. In R. D. Rogers \& K. E. Seddon (Eds.), Ionic Liquids as green solvents: Progress and Prospects (Vol. 856, Chap. 3, pp. 32-40). Washington DC: American Chemical Society. http://dx.doi.org/10.1021/bk-2003-0856.ch003

Reichenauer, G., \& Scherer, G. W. (2001). Nitrogen sorption in aerogels. J. Non-Cryst. Solids, 285(1-3), 167-174. http://dx.doi.org/10.1016/S0022-3093(01)00449-5

Schwertfeger, F., Glaubitt, W., \& Schubert, U. (1992). Hydrophobic aerogels from $\mathrm{Si}(\mathrm{OMe})_{4} / \mathrm{MeSi}(\mathrm{OMe})_{3} \mathrm{mix}-$ tures. J. Non-Cryst. Solids, 145, 85-89. http://dx.doi.org/10.1016/S0022-3093(05)80435-1 
Shi, F., Zhang, Q., Li, D., \& Deng, Y. (2005). Silica-Gel-Confined Ionic Liquids: A New Attempt for the Development of Supported Nanoliquid Catalysis. Chem. Eur. J., 11(18), 5279-5288. http://dx.doi.org/10.1002/chem.200500107

Venkateswara, A. R., \& Pajonk, G. M. (2001). Effect of methyltrimethoxysilane as a co-precursor on the optical properties of silica aerogels. J. Non-Cryst.Solids, 285(1-3), 202-209. http://dx.doi.org/10.1016/S00223093(01)00454-9

Vioux, A., Viau, L., Volland, S., \& Le Bideau, J. (2010). Use of ionic liquids in sol-gel; ionogels and applications. C. R. Chimie, 13(1-2), 242-255. http://dx.doi.org/10.1016/j.crci.2009.07.002

Zhang, J., Zhang, Q., Li, X., Liu, S., Ma, Y., Shi, F., \& Deng, Y. (2010). Nanocomposites of ionic liquids confined in mesoporous silica gels: preparation, characterization and performance. Phys. Chem. Chem. Phys., 12, 1971-1981. http://dx.doi.org/10.1039/B920556J

Zhou, Y., Schattka, J. H., \& Antonietti, M. (2004).Room-Temperature Ionic Liquids as Template to Monolithic Mesoporous Silica with Wormlike Pores via a Sol61Gel Nanocasting Technique. Nano Letters, 4(3), 477481. http://dx.doi.org10.1021/n1025861f

\section{Copyrights}

Copyright for this article is retained by the author(s), with first publication rights granted to the journal.

This is an open-access article distributed under the terms and conditions of the Creative Commons Attribution license (http://creativecommons.org/licenses/by/3.0/). 